\title{
Zinc Oxide as a Standard Substance in the Solution Calorimetry of Portland Cement
}

\author{
Edwin S. Newman
}

(May 10, 1962)

\begin{abstract}
Zinc oxide is the standard substance specified for calibrating the heat-of-solution calorimeters used in determining the heat of hydration of portland cement in several American and foreign cement specifications. The heats of solution of zinc oxide samples from different sources and after different heat treatments have been determined in the standard mixture of nitric and hydrofluoric acids. It is concluded that the value given in the specifications is low, that heat treatment in the range 310 to $950{ }^{\circ} \mathrm{C}$ is not critical, that small variations in the $\mathrm{ZnO} /$ acid weight ratio are without significance, and that analytical-reagent zine oxide from various sources may safely be used. The mean value obtained for the heats of solution of zinc oxide from twelve sources determined in triplicate in $1.00 \mathrm{H} \mathrm{NO}_{3}, 0.284 \mathrm{HF}, 26.38 \mathrm{H}_{2} \mathrm{O}$ at a $\mathrm{ZnO} /$ acid weight ratio of $7 / 425$ at $25{ }^{\circ} \mathrm{C}$ was $257.82 \mathrm{cal} / \mathrm{g}$ with a standard error of 0.015 $\mathrm{cal} / \mathrm{g}$. The thermochemical calorie of 4.1840 joules is used. The temperature coefficient based on least-square fitting to 16 data points obtained in an earlier study was -0.087 $\mathrm{cal} / \mathrm{g}$-deg, with a computed standard error of $0.013 \mathrm{cal} / \mathrm{g}-\mathrm{deg}$. The corresponding values for heat of solution and temperature coefficient given in the specifications are $256.6 \mathrm{cal} / \mathrm{g}$ and $-0.1 \mathrm{cal} / \mathrm{g}$-deg, respectively.
\end{abstract}

\section{Introduction}

Several specifications $[1,2,3]^{1}$ require the use of zinc oxide as the standard substance for calibrating the heat-of-solution calorimeters by which the heat of hydration of portland cement is determined. For this purpose the heat of solution of $\mathrm{ZnO}$ has been determined $[4,5]$ in the mixture of nitric and hydrofluoric acids used in measuring the heats of solution of cements and cement pastes. Roth and Chall [6] and Peppler and Newman [7] have also determined the heat of solution of zinc oxide in hydrochloric acid.

The heat of solution of $\mathrm{ZnO}$ in the nitric-hydrofluoric acid mixture was given by Stenzel and Morris [4] as $256.1 \mathrm{cal} / \mathrm{g}$ without reference to the temperature of reaction, although it is believed that the final temperature of their calorimeter was $31.5{ }^{\circ} \mathrm{C}$ [8, p. 589]. They calibrated their calorimeter electrically but did not define their calorie. It is believed that the calorie of 4.1833 international joules was used. Elsewhere throughout this paper the defined thermochemical calorie of 4.1840 joules (4.1833 international joules) is used.

Shartsis and Newman [5] determined the isothermal heat of solution of $\mathrm{ZnO}$ over the temperature range 20 to $35^{\circ} \mathrm{C}$ and reported a temperature coefficient of $-0.1 \mathrm{cal} / \mathrm{g}$-deg. Newman [9] made a few measurements at two $\mathrm{ZnO}$ /acid ratios and reported a relationship between heat of solution and sample weight. No other independent determinations of the heat of solution of zinc oxide in nitric-hydrofluoric acid have been found, other authors having accepted the specification value of $256.6 \mathrm{cal} / \mathrm{g}$ at $25^{\circ} \mathrm{C}[1,5]$.

Recently the American Society for Testing Materials has directed attention to the improvement of the simple vacuum-flask cement calorimeter by the

Figures in brackets indicate the literature references at the end of this paper. use of an isothermal jacket and by other means. In the course of tests, new measurements of the heat of solution of $\mathrm{ZnO}$ were made by the author and are reported below. Since these values differed from the published measurements, the original data from this laboratory [5, 9] were re-examined, and those heats of solution were recalculated, using in so far as possible the current method of determining the corrected temperature rise of the calorimeter. In the current procedure, bridge-dial corrections are used, and the time-resistance (temperature) values used in computation are taken from large-scale smooth curves drawn through the observed values. The bridge corrections were not determined in the earlier work and were not available for the recalculation. The calibration experiments on which this earlier work was based were also recalculated, and the revised energyequivalent values obtained were used in the computations.

Before an individual lot of $\mathrm{ZnO}$ is used in a series of calibration experiments, it is sintered by heating for one hour at $950{ }^{\circ} \mathrm{C}$ to reduce the surface $[1,2]$ and ground, tediously, by hand, to pass a No. 100 sieve. During this grinding, moisture which must be removed is gained from the atmosphere, and a second heating is required. Measurements were made of the heats of solution of samples of zinc oxide which had not been ground and reheated, but which had simply been heated for $2 \mathrm{hr}$ to various temperatures and introduced into the calorimeter after cooling in a desiccator over magnesium perchlorate and weighing.

In this investigation of the heat of solution of zinc oxide in a nitric-hydrofluoric acid mixture of a single composition, the effects of a number of variables were considered. On single lots of zinc oxide, the effects of varying the temperature of heating, the time of heating at $950{ }^{\circ} \mathrm{C}$, and the $\mathrm{ZnO} /$ acid 
weight ratio, and of different batches of $2.00 \mathrm{~N}$ nitric acid were examined. The heats of solution of zinc oxide lots from widely separated sources were measured. As a check on the calorimeter assembly and operation, the heat of solution of $\mathrm{KCl}$ in water was determined for comparison with published values.

\section{Materials, Apparatus, and Procedure}

Three 50-liter batches of $2.00 \mathrm{~N}$ nitric acid were prepared at different times and stored in a 50-liter polyethylene bottle while being used. The acid was standardized volumetrically against $\mathrm{NaOH}$ solution and potassium acid phthalate (NBS Standard Sample No. 84b).

Twelve different lots of zinc oxide were used, seven from the United States, two each, by different manufacturers, from England and Germany, and one from Japan. One, from the United States, the only sample not of reagent grade, was the Rubber Reserve Standard for the compounding of rubber. Two others, NBS Standard Sample $370 \mathrm{~A}$ and one intended for the NBS Standard Sample 370 B but rejected on the basis of compounding tests, were also manufactured for the test compounding of rubber. Both were of analytical-reagent grade. All the others were reagent-grade chemicals in the country of their origin, and are there used to calibrate cement calorimeters.

The composition and properties of sample $370 \mathrm{~A}$ were as follows, as given by the manufacturer at the time of its establishment as a standard material for the compounding of rubber:

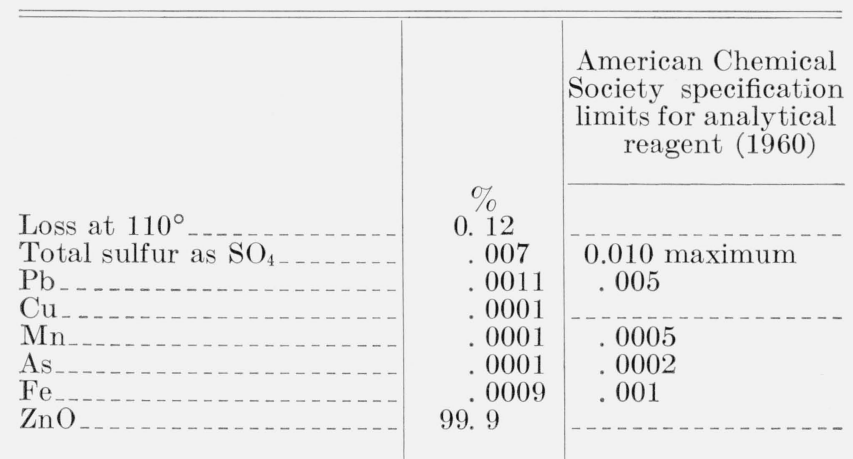

This material passed the American Chemical Society specification tests for material insoluble in sulfuric acid $(<0.010 \%)$, alkalinity, chlorides $(<0.001 \%)$, and nitrates $(<0.003 \%)$. The specific surface of the original material as determined by nitrogen adsorption was $3.3 \mathrm{~m}^{2} / \mathrm{g}$. After sintering for $1 \mathrm{hr}$ at $950{ }^{\circ} \mathrm{C}$ and grinding to pass a No. 100 sieve, the surface determined by nitrogen adsorption in this laboratory was $1.7 \mathrm{~m}^{2} / \mathrm{g}$.

About a third of the heat-of-solution measurements, namely those concerned with the effect of different heating temperatures and part of those made with differing sample weights, was made on one lot of zinc oxide. The remaining measurements were made, generally in sets of four replicate determinations, on the various lots of zinc oxide subjected to the standard treatment of heating and grinding A single lot which had been heated for $17 \mathrm{hr}$, instead of $1 \mathrm{hr}$, at $950{ }^{\circ} \mathrm{C}$ was also tested.

Analytical-reagent potassium chloride was recrystallized twice, dried at $200{ }^{\circ} \mathrm{C}$, and passed through a No. 30 sieve. Its heat of solution in distilled water was determined at a nominal $\mathrm{H}_{2} \mathrm{O} / \mathrm{KCl}$ molar ratio of 1,500 .

An improved platinum calorimeter reaction vessel, described elsewhere [10], was used in the isothermal jacket of the calorimeter described in earlier papers, $[11,12]$. The calorimeter fluid was $14 \mathrm{ml}$ of $48-$ percent $\mathrm{HF}$ solution and enough $2.00 \mathrm{~N} \mathrm{HNO}_{3}$ to make a total charge of $740.00 \mathrm{~g}$. The calorimeter was operated in a 30 -liter water bath at $25.4{ }^{\circ} \mathrm{C}$ $\left(25.0{ }^{\circ} \mathrm{C}\right.$ in the later work) controlled to $\pm 0.002{ }^{\circ} \mathrm{C}$ during a determination. The water bath and the instruments were in a constant temperature room generally controlled at $25.5 \pm 0.5^{\circ} \mathrm{C}$. The temperature measurements were made using a platinum resistance thermometer in a platinum envelope. A G-1 Mueller bridge was used with a type HS galvanometer with an 8-m light beam. Measured resistances were recorded to $10 \mu \mathrm{ohms}$, corresponding to a galvanometer scale deflection of $1 \mathrm{~mm}$. At small rates of temperature change the sensitivity was doubled by reversing the bridge current. A current of $8 \mathrm{ma}$ was used, corresponding to $4 \mathrm{ma}$ in the resistance thermometer. The effect of this current on the thermometer resistance was quite apparent, and the measurements were generally made not less than 110 sec after the bridge current was turned on, in order to allow the thermometer resistance to attain its steady-state value. The scale zero was determined after each 2-min temperature reading, either by switching off or by reversing the bridge current.

The bridge was calibrated in place just before the heat-of-solution measurements were begun. The $\mathrm{K}-2$ potentiometer, the standard cell, standard resistance, and volt box used in measuring the electrical-energy input were calibrated by the Electricity Division of the National Bureau of Standards. For the early calibrations (see table 1), the electrical heating of the calorimeter was timed automatically on a chronograph paced by the standard seconds signal of the NBS. When the chronograph was used, electrical heating times were about $9 \mathrm{~min}$, and the total error in measuring the tape was probably no larger than \pm 0.03 sec. Most of the calibrations, however, were made by turning the current on and off by means of a relay activated by the seconds signal. Oscilloscopic measurements showed a net correction of -7 msec to the nominal time indicated by the individual seconds pulses which turned on and turned off the calorimeter heating current. The calorimeter was operated as nearly as possible between the same two temperatures in all experiments with a given weight of zinc oxide, and was generally calibrated between these temperatures also, usually beginning and ending within $0.02 \mathrm{deg} \mathrm{C}$ of the two selected temperatures. The final temperature was generally within a few hundredths of a degree $\mathrm{C}$ of the bath temperature. 
( 1 calorie $=4.1840$ joules $)$

\begin{tabular}{|c|c|c|c|c|c|c|}
\hline \multirow[b]{2}{*}{ Number } & \multirow{2}{*}{$\begin{array}{l}\text { Calorimeter } \\
\text { fluid }\end{array}$} & \multirow{2}{*}{$\begin{array}{l}\text { Average a calo- } \\
\text { rimeter tempera- } \\
\text { ture }\left(\theta_{\text {avg }}\right)\end{array}$} & \multirow{2}{*}{$\begin{array}{l}\text { Heating } \\
\text { rate }\end{array}$} & \multirow{2}{*}{$\begin{array}{l}\text { Tempera- } \\
\text { ture rise }\end{array}$} & \multicolumn{2}{|c|}{ Energy equivalent } \\
\hline & & & & & Average value & $\begin{array}{l}\text { Standard } \\
\text { error }\end{array}$ \\
\hline $\begin{array}{l}1353-59 \text { b, с } \\
1652-59 \text { с } \\
1719-23 \\
1724-28 \\
1730-36 \\
1773 \mathrm{~A} \text { to } 1775 \mathrm{~F} \mathrm{~d} \\
1779-82 \\
1783-86 \\
1837-41 \\
1842\end{array}$ & $\begin{array}{l}\text { Acid } \mathrm{O}^{\mathrm{b}} \\
\text { Acid A } \\
\text { Acid } \mathrm{B} \\
\text { Acid } \mathrm{B} \\
\text { Acid } \mathrm{B} \\
\text { Acid } \mathrm{C} \\
\text { Water } \\
\text { Water } \\
\text { Water } \\
\text { Water }\end{array}$ & $\begin{array}{c}\text { Ohm } \\
2.5767-2.5771 \\
2.4552-2.4688 \\
2.4160-2.4422 \\
2.3634-2.3690 \\
2.5334-2.5389 \\
1.9470-2.6920 \\
2.5314-2.5493 \\
2.5329-2.5345 \\
2.5820-2.5880 \\
2.5860-2.5889\end{array}$ & $\begin{array}{l}c a l / s e c \\
0.78 \\
3.8 \\
3.8 \\
3.8 \\
.95 \\
.92 \\
3.7 \\
.93 \\
.52 \\
.23\end{array}$ & $\begin{array}{c}{ }^{\circ} C \\
0.7 \\
3.3 \\
3.3 \\
4.4 \\
1.0 \\
1.0 \\
1.0 \\
1.0 \\
0.15 \\
.15\end{array}$ & $\begin{array}{l}24088^{j / o h m} \\
27967.6 \\
27974.5 \\
27976.5 \\
28006.5 \\
27519.5+195.5 \theta_{\text {avg }} \\
31994.4 \\
31992.9 \\
32081 \\
32026\end{array}$ & $\begin{array}{r}j / 0 h m \\
5 \\
4.2 \\
4.6 \\
4.1 \\
7.0 \\
4.5 \\
6.6 \\
39 \\
9\end{array}$ \\
\hline
\end{tabular}

a Bridge dial readings, add $25.5 \mathrm{ohms.} \mathrm{At} 25^{\circ} \mathrm{C}, \theta_{\mathrm{avg}}=2.61 \mathrm{ohm}, d R / d T=0.1010 \mathrm{ohm} / \mathrm{deg}$.

b Data obtained with calorimeter containing $600.0 \mathrm{~g}$ of an earlier batch of acid. J. Research NBS 62 207-211 (1959) R P2955.

c Timed by chronograph. All other calibrations timed by relay.

d 5 consecutive 1-deg rises per determination.

- Measurements by operator B. All others by operator A.

Three 50-liter batches of $2.00 \mathrm{~N} \mathrm{HNO}_{3}$ were used. With acid from the first (acid $\mathrm{A}$ ) batch, the calorimeter was calibrated using the chronograph, with the second (acid B) and third (acid C), using the relay. For use with acid C, the calorimeter was calibrated three times over five consecutive 1-deg temperature rises from 20 to $25^{\circ} \mathrm{C}$, using the final rating period for one increment as the initial rating period for the next. The least-squares linear equation relating the observed energy equivalent to the average calorimeter temperature as indicated by the resistance thermometer was calculated from the 15 points obtained. Since all heat-of-solution determinations ended near the bath temperature, different average temperatures were obtained with different weight samples, and the equation was used to calculate the energy equivalent to be used. By this procedure otherwise necessary large differences in either electrical-heating rates or times were not involved in the comparison of heats of solution of different weight samples of zinc oxide.

The energy equivalent was determined with the calorimeter containing only the mixed acids. The sample when added was at a temperature near to the final calorimeter temperature, and the heat it carried into the calorimeter was accounted for by the heat capacity of the sample and the small temperature difference involved. This procedure is equivalent to the use of the heat capacity of the reactants in calculating the heat of reaction. The result, therefore, is the isothermal heat of reaction (solution) at the final temperature of the calorimeter.

The temperatures at the beginning, middle, and end of the two 20-min rating periods of each calorimetric determination were obtained from smooth deviation curves drawn through the recorded data plotted at a scale of $1.5 \mathrm{~mm}=10 \mu \mathrm{ohms}$. Experimental periods [13, p. 38] of $20 \mathrm{~min}$ were used for heat-of-solution experiments, and periods of 20 to $30 \mathrm{~min}$ were used for calibration experiments. The corrected temperature rise in ohms was calculated using the Second Geophysical Laboratory Method described by White [13, p. 42].
The temperature of the interior of the balance was taken as the temperature of the sample at the time of its introduction into the calorimeter through a funnel. Tests showed that a thermometer in the balance case and one immersed in the sample indicated essentially the same temperature. The specific heat of $\mathrm{ZnO}$ was taken as $0.12 \mathrm{cal} / \mathrm{g}$ - $\mathrm{deg}$ [14], and the correction for the sensible heat carried into the calorimeter with the sample averaged $-0.051 \mathrm{cal} / \mathrm{g}$. Extreme values of -0.127 and $+0.046 \mathrm{cal} / \mathrm{g}$ were obtained with the exception of seven values ranging from -0.138 to $-0.289 \mathrm{cal} / \mathrm{g}$ reached during two brief periods in July when the air conditioner was not operating properly.

Heats of solution recorded in this paper are corrected to $25.0{ }^{\circ} \mathrm{C}$ from the final calorimeter temperature, using -0.09 and $-0.48 \mathrm{cal} / \mathrm{g}$-deg for the temperature coefficients of the heats of solution of $\mathrm{ZnO}$ and $\mathrm{KCl}[18]$, respectively. The measurements of the effect of temperature of heating on the heat of solution of $\mathrm{ZnO}$ were made at the rate of two measurements per day in a series such that each treatment was measured once in the morning and once in the afternoon, but not twice on the same day. The series was then repeated. The various standardtreated samples were measured at the rate of four a day, programed so that none was measured twice on the same day or twice at the same (2-hr) period during the day.

\section{Results and Discussions}

\subsection{New Data \\ a. Calibrations}

The electrical calibrations made in this work are reported in table 1. ${ }^{2}$ For these various calibrations,

2 Standard deviation of the average, standard error, is given here and elsewhere in this paper, calculated by the formula

$$
s=\sqrt{\frac{\Sigma x^{2}-(\Sigma x)^{2} / n}{n(n-1)}},
$$

where $x$ is the individual observation, and $n$ is the number of observations. Where data in this paper is given in the form $a \pm b$, $a$ represents the mean value and $b$, the standard error of $a$. Also for the comparison of two averages the $t$-test was used at the 5 percent level of significance [15]. 
the applied voltage was adjusted so that each rise was generally accomplished by heating times of 9 to $13 \mathrm{~min}$. The heating rates for calibrations with acid varied by a factor of about four, as did the temperature intervals over which the calibrations were made. No effect of heating rate on the energy equivalent was evident which could be separated from effects of different acid batches or from the increase of energy equivalent with average temperature. A perceptible effect of heating rate would be expected if systematic error were present in the electrical heating. As a further check, the calorimeter, charged with $740.00 \mathrm{~g}$ of water, was calibrated over a 1-deg temperature interval ending near the bath temperature at two heating rates differing by a factor of about four, see table 1, Nos. 1779-1786. No significant effect was found at these rates. For

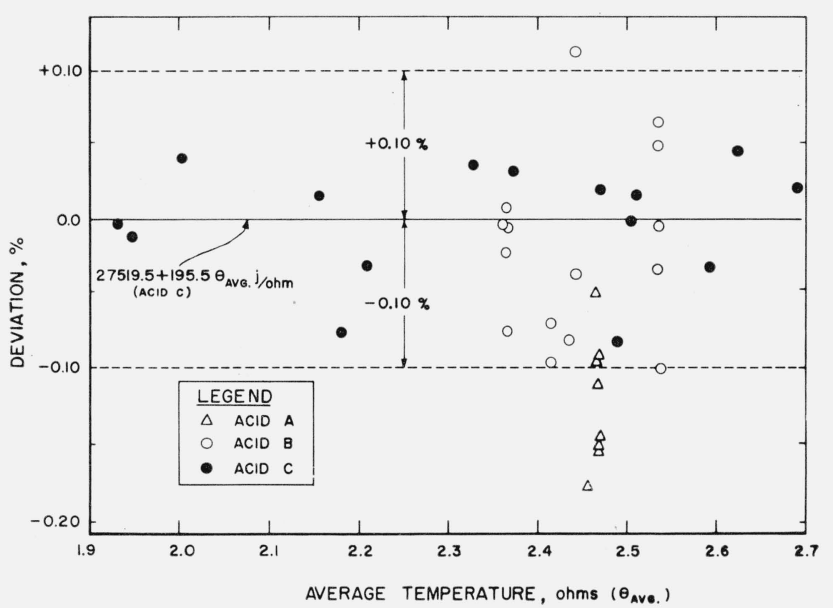

FIguRE 1. Electrical calibration of calorimeter containing nitric-hydrofluoric acid.

Results for three batches are shown.

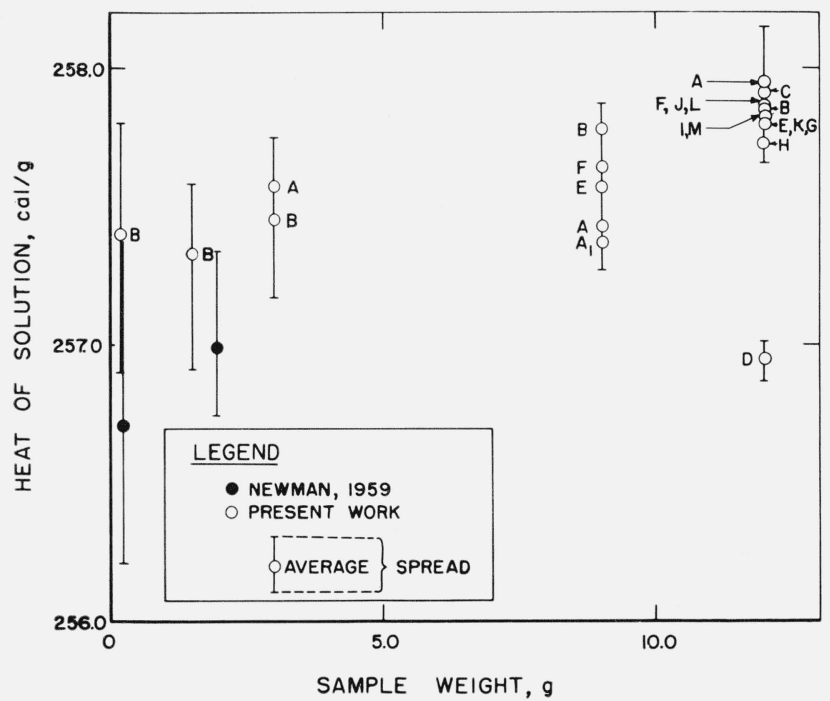

FIGURE 2. Effect of $\mathrm{ZnO} /$ acid weight ratio on the heat of solution of zinc oxide in nitric-hydrofluoric acid.

The zinc oxide was heated $1 \mathrm{hr}$ at $950{ }^{\circ} \mathrm{C}$, ground to pass a No. 100 sieve, and reheated for $5 \mathrm{~min} \quad(1 \mathrm{cal}=4.1840 \mathrm{j})$. determining the heat of solution of $\mathrm{KCl}$, the calorimeter was calibrated for a temperature rise of about $0.15^{\circ} \mathrm{C}$ at heating rates of about one-half and onequarter of the smaller of the two rates used for the 1-deg experiments. These data are also given in table 1, Nos. 1837-1848. The energy equivalents obtained by these two smaller rates differed by about 0.2 percent. Contributing to this difference is the fact that the 0.15 -deg experiments at the faster rate were performed by a different operator. The energy equivalent obtained for a 0.15 -deg rise at the slower rate was about 0.07 percent higher than the value obtained by the same operator for a 1 -deg rise at 16 times the heating rate, when both energy equivalents were calculated at the same average temperature by means of the temperature coefficient shown in table 1 (No. $1773 \mathrm{~A}-1775 \mathrm{~F}$ ). This 0.07 percent difference might be attributable to the 16 -fold difference in heating rate.

Figure 1 shows the results of calibrations made with nitric-hydrofluoric acid solution in the calorimeter. A least-squares linear equation for the relationship between the energy equivalent found using acid $\mathrm{C}$ and the average calorimeter temperature in ohms was calculated from the data in table 1. This equation

$$
E=27519.5+195.5 \theta_{\text {avg }}
$$

where $E$ is $\mathrm{j} / \mathrm{ohm}$, and $\theta_{\text {avg }}$ is average dial reading in ohms, is plotted in figure 2 as a straight horizontal line. The individual determinations from which the line was calculated, and the rest of the values for acids $\mathrm{A}, \mathrm{B}$, and $\mathrm{C}$ given in table 1 , are shown in figure 1 , deviations from the line in percentage being plotted as ordinates against the average temperature in ohms as the abscissas. Acid A, for which the calorimeter was calibrated by chronograph, is seen to be generally about 0.1 percent low compared with the other two. ${ }^{3}$

\section{b. Heats of Solution, Potassium Chloride in Water}

The results of the measurements of the heat of solution of recrystallized potassium chloride in water are given in table 2. Results obtained for a different lot of reagent, not recrystallized, are also given. The average values for the recrystallized salt are larger than the tentative "best" value of $\Delta \mathrm{H}_{\infty}^{\circ}=4115 \mathrm{cal} / \mathrm{mole}$ recently reported [19].

\section{c. Zinc Oxide in Nitric-Hydrofluoric Acid}

The results of the measurements of the heats of solution of 9 -g samples of zine oxide $\mathrm{A}$ heated for $2 \mathrm{hr}$ at $150,310,660$, and $950^{\circ} \mathrm{C}$ are given in table 3 . These samples do not show the reduction in heat of solution with increased temperature of heating found

3 The reason for this difference is not known. An error of about 0.03 [16] in adjusting the normality of this batch of acid would account for the difference but seems excessive. Tests have shown no significant difference in timing between chronograph and relay. 
TABLE 2. Heat of solution of $\mathrm{KCl}$ in water

( 1 calorie $=4.1840$ joules $)$

\begin{tabular}{|c|c|c|c|}
\hline Lot_... & A & B (Recrystallized) & B (Recrystallized) \\
\hline $\begin{array}{l}\text { Operator. } \\
\text { Numbers } \\
\text { Final temperature }\left(\theta_{3}\right) \\
\text { Sample temperature }\left(\theta_{r}\right)^{\mathrm{a}} \\
n \text { b } \\
\text { Correction for sample temperature }{ }^{\mathrm{c}} \mathrm{cal} / \mathrm{g} \\
\text { Correction to } 25{ }^{\circ} \mathrm{C} \mathrm{d} \\
\text { Heat of solution at } 25^{\circ} \mathrm{C} \\
\Delta H^{\circ}{ }^{\mathrm{e}}\end{array}$ & $\begin{array}{c}\text { B } \\
1803 \text { to } 06 \\
24.80 \text { to } 24.82 \\
25.35 \text { to } 25.90 \\
1017.6 \text { to } 1021.1 \\
-0.089 \text { to }-0.178 \\
+0.083 \text { to }+0.096 \\
-56.495 \text { to }-56.669 \\
-4212.1 \text { to }-4225.1 \\
4146 \pm 3 \text { f }\end{array}$ & $\begin{array}{c}\text { B } \\
1837 \text { to } 42 \\
24.84 \text { to } 25.00 \\
24.90 \text { to } 27.00 \\
1491.4 \text { to } 1496.5 \\
+0.008 \text { to }-0.348 \\
0 \text { to }+0.077 \\
-56.043 \text { to }-56.273 \\
-4178.4 \text { to }-4195.5 \\
4122 \pm 5 \text { f }\end{array}$ & $\begin{array}{c}\text { A } \\
1843 \text { to } 46 \\
24.88 \\
25.30 \text { to } 25.50 \\
1492.6 \text { to } 1495.5 \\
-0.069 \text { to }-0.102 \\
\text { +0.056 } \\
-56.127 \text { to }-56.241 \\
-4184.7 \text { to }-4193.2 \\
4125 \pm 2\end{array}$ \\
\hline
\end{tabular}

a Temperature in balance case.

b Moles $\mathrm{H}_{2} \mathrm{O} /$ moles $\mathrm{KCl}=(740.00 / 18.016) /[($ Sample weight $) / 74.557]$.

c $-0.165\left(\theta_{\tau}-\theta_{3}\right)$ NBS Circular 500.

$\mathrm{d}+0.48\left(25.00-\theta_{3}\right)$ J. Coops, G. Somsen, and M. W. Tolk, Calorimetry Conference, Ottawa (1961)

e Corrections to heat of solution for $n=1,000$ and 1,500 are negligible. Corrections to $\Delta H$ for $n=\infty$ are -71 and -63 cal/mole for $n=1,000$ and 1,500 respectively, V. Barfield, Calorimetry Conference, Ottawa (1961).

f Standard error.

TABLE 3. Heat of solution of zinc oxide " $A$ " heated for 2 hr at various temperatures ${ }^{a}$

$(1$ calorie $=4.1840$ joules $)$

\begin{tabular}{|c|c|c|c|c|}
\hline Number & $150^{\circ} \mathrm{C}$ & $310^{\circ} \mathrm{C}$ & $660^{\circ} \mathrm{C}$ & $950^{\circ} \mathrm{C}$ \\
\hline $\begin{array}{l}1 \\
2 \\
3 \\
4 \\
5\end{array}$ & $\begin{array}{c}c a l / g \\
256.95 \\
256.82 \\
256.80 \\
256.88 \\
\text { b } 256.97\end{array}$ & $\begin{array}{c}c a l / g \\
257.40 \\
257.55 \\
256.90 \\
257.29\end{array}$ & $\begin{array}{c}c a l / g \\
257.61 \\
257.20 \\
257.06 \\
257.32 \\
\text { ь } 257.28\end{array}$ & $\begin{array}{c}c a l / g \\
257.35 \\
257.33 \\
257.03 \\
257.27\end{array}$ \\
\hline $\begin{array}{l}\text { Average } \\
\text { S.D. Avg }\end{array}$ & $\begin{array}{r}256.88 \\
0.034\end{array}$ & $\begin{array}{r}257.28 \\
0.139\end{array}$ & $\begin{array}{r}257.29 \\
0.090\end{array}$ & $\begin{array}{r}257.25 \\
0.073\end{array}$ \\
\hline
\end{tabular}

a 9 -g samples.

b Omitted from variance analysis.

TABLE 4. Residual ignition loss a of zinc oxide " $A$ " after heuting for $2 \mathrm{hr}$ at various temperatures

\begin{tabular}{|c|c|c|c|c|}
\hline Number & Unheated $\mathrm{b}$ & $150^{\circ} \mathrm{C}$ & $310^{\circ} \mathrm{C}$ & $660^{\circ} \mathrm{C}$ \\
\hline $\begin{array}{l}1 \\
2 \\
3 \\
4\end{array}$ & $\begin{array}{c}\% \\
0.243 \\
.245 \\
.241 \\
.246 \\
\end{array}$ & $\begin{aligned} \% \\
0.133 \\
.129 \\
.139 \\
.134 \\
.139\end{aligned}$ & $\begin{array}{c}\% \\
0.057 \\
.056 \\
.056 \\
.058 \\
\end{array}$ & $\begin{array}{r}\% \\
0.020 \\
.017 \\
.018 \\
.011 \\
.016\end{array}$ \\
\hline A verage & 0.244 & 0.135 & 0.057 & 0.016 \\
\hline
\end{tabular}

a Calculated ignition loss if sample were heated at $950^{\circ} \mathrm{C}$.

b Observed loss at $950^{\circ} \mathrm{C}$.

TABLE 5. Calculated heat of solution of zinc oxide " $A$ " after heating for $2 \mathrm{hr}$ at various temperatures ${ }^{\text {a }}$

( 1 calorie $=4.1840$ joules)

\begin{tabular}{|c|c|c|c|c|}
\hline Number & $150^{\circ} \mathrm{C}$ & $310^{\circ} \mathrm{C}$ & $660^{\circ} \mathrm{C}$ & $950^{\circ} \mathrm{C}$ \\
\hline $\begin{array}{l}1 \\
2 \\
3 \\
4 \\
5\end{array}$ & $\begin{array}{c}c a l / g \\
257.29 \\
257.15 \\
257.16 \\
257.22 \\
\text { b } 257.32\end{array}$ & $\begin{array}{c}\text { cal } / g \\
257.54 \\
257.69 \\
257.04 \\
257.44\end{array}$ & $\begin{array}{c}c a l / g \\
257.66 \\
257.24 \\
257.10 \\
257.34 \\
\text { b } 257.32\end{array}$ & $\begin{array}{c}c a l / g \\
257.35 \\
257.33 \\
257.03 \\
257.27\end{array}$ \\
\hline $\begin{array}{l}\text { Average } \\
\text { S.D. Avg }\end{array}$ & $\begin{array}{c}257.23 \\
0.049\end{array}$ & $\begin{array}{c}257.43 \\
0.140\end{array}$ & $\begin{array}{c}257.34 \\
0.092\end{array}$ & $\begin{array}{r}257.25 \\
0.072\end{array}$ \\
\hline
\end{tabular}

a Basis: weight ignited at $950^{\circ} \mathrm{C}$

b Omitted from variance analysis. by Roth and Chall [6] with hydrochloric acid. These investigators heated their samples for $4 \mathrm{hr}$. It may be that $2 \mathrm{hr}$, although twice the "standard" heating time, is not long enough to affect the heat of solution significantly. Note, however, the results in table 6 for lot $\mathrm{H}$ showing that $17 \mathrm{hr}$ at $950{ }^{\circ} \mathrm{C}$ had no appreciable effect. The values in table 3 are calculated on the basis of the actual weight of the zinc oxide after the heat treatment. Table 4 gives the calculated residual loss on ignition of each sample, i.e., the percentage that would be lost if the sample were thereafter heated at $950{ }^{\circ} \mathrm{C}$.

Table 5 gives the heats of solution from table 3, recalculated on the $950{ }^{\circ} \mathrm{C}$ ignited basis. These recalculated data show a slight decrease in heat of solution with increase of temperature of heating. The decrease, however, is not significant. On the basis of the data in tables 3 and 5 , it is concluded that for calibration of the cement calorimeter the temperature of heating of the zinc oxide is not critical, providing it is $310^{\circ} \mathrm{C}$ or more and not over $950{ }^{\circ} \mathrm{C}$.

In performing an analysis of variance on data from table 3 , it was found that temperature, test series, and their interaction are significant at the 5-percent probability level. However, if the $150{ }^{\circ} \mathrm{C}$ data are omitted, none of these factors or interaction are significant at the 5-percent probability level, and the 12 values vield an average of $257.28 \mathrm{cal} / \mathrm{g}$ with a standard error of $0.059 \mathrm{cal} / \mathrm{g}$. Data from table 5 were similarly treated, and it was found that none of the main factors or interaction are significant at the 5 -percent probability level. The 16 values yield an average of $257.30 \mathrm{cal} / \mathrm{g}$ with a standard error of 0.050 $\mathrm{cal} / \mathrm{g}$. Note that all measurements to determine the effect of temperature of heating for $2 \mathrm{hr}$ were performed with 9-g samples of zinc oxide lot $\mathrm{A}$ in calorimeter acid batch $\mathrm{A}$.

Table 6 gives a summary of all the measurements of the heats of solution of different lots of zinc oxide subjected to the standard treatment of heating $1 \mathrm{hr}$ at $950{ }^{\circ} \mathrm{C}$, grinding to pass a No. 100 sieve, and reheating for $5 \mathrm{~min}$ at $950{ }^{\circ} \mathrm{C}$. The values in this table are significantly higher than those previously reported for zinc oxide $[4,5,9]$, except those for lot D 
TABLE 6. Heat of solution of zinc oxide in nitric-hydrofluoric acid mixture ${ }^{\mathrm{a}, \mathrm{b}}$

( 1 calorie $=4.1840$ joules $)$

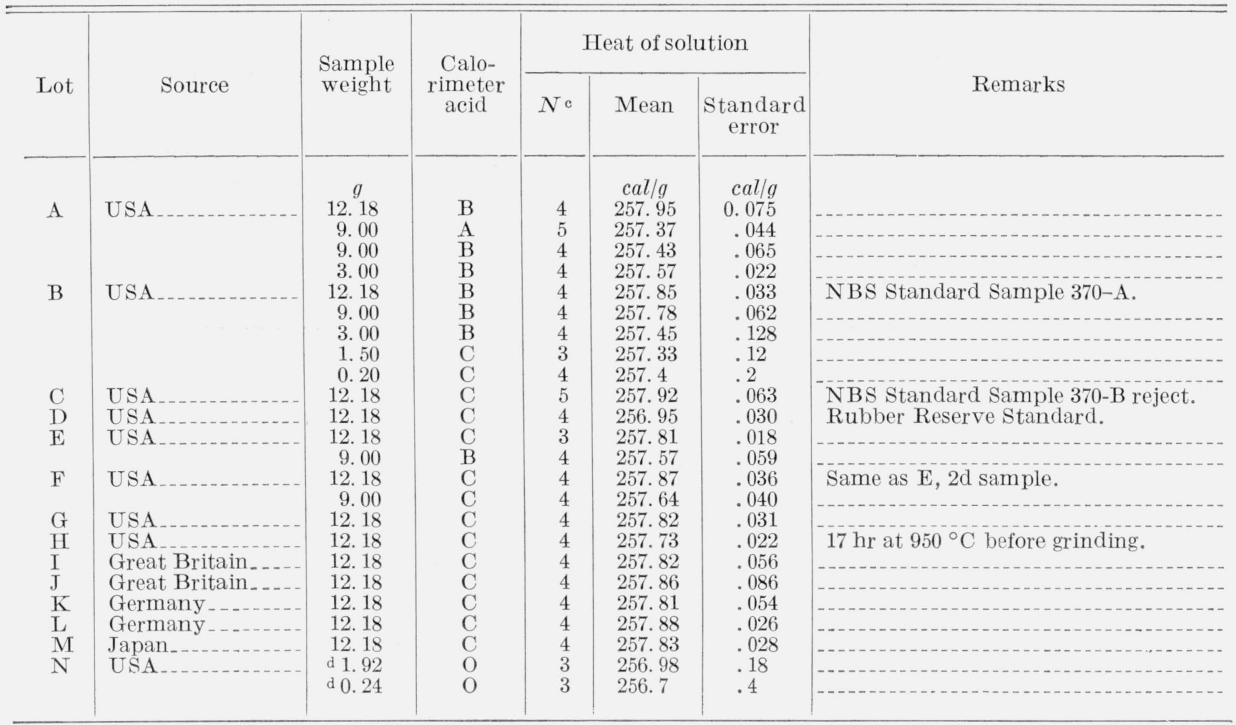

a Zinc oxide heated $1 \mathrm{hr}$ at $950^{\circ} \mathrm{C}$, ground to pass No. 100 sieve, reheated $5 \mathrm{~min}$, cooled in a desiccator.

b Acid mixture, $740.00 \mathrm{~g}\left(1.36 \mathrm{HNO}_{3}, 0.386 \mathrm{HF}, 35.88 \mathrm{H}_{2} \mathrm{O}\right)$.

c Number of determinations. RP2955.

which was not reagent grade. The data for the $12-\mathrm{g}$ samples, the proper sample weight to give the correct $\mathrm{ZnO} /$ acid ratio in $740.00 \mathrm{~g}$ of acid, were subjected to analysis of variance. It was found that the first determination each day gave a significantly high mean value. The mean value of these 12 measurements was $257.92 \mathrm{cal} / \mathrm{g}$ with a standard error of 0.033 $\mathrm{cal} / \mathrm{g}$. Lot D was not included in the analysis. The analysis was repeated excluding the first determination each day, and there were found no significant differences among the 12 samples and no significant variation with time of day. The mean value for the 12 samples measured in triplicate was $257.82 \mathrm{cal} / \mathrm{g}$ at $25^{\circ} \mathrm{C}$ with a standard error of $0.015 \mathrm{cal} / \mathrm{g}$. The $0.10-\mathrm{cal} / \mathrm{g}$ higher average value found for the first sample each day may have been due to inadequate cooling in the desiccator, since this sample was usually cooled for about an hour instead of the two or more hours for subsequent samples. The change in weight during the additional 1-hr storage in the desiccator was about 0.01 percent, one quarter of the percentage change in the heat of solution. Parker and Nurse [17], desiccating with $\mathrm{CaCl}_{2}$, found a somewhat larger change in weight.

Included in the data in table 6 are heats of solution obtained with different weights of sample. Figure 2 shows these data, including all determinations. The individual points in this figure are the mean values from table 6 . The vertical lines show the total spread of all determinations at a given weight, 48 determinations in the case of the twelve $12-\mathrm{g}$ samples plotted together. The progressively poorer precision as the sample size decreases is apparent in the figure if a comparison is made between the spread for the four determinations for zinc oxide $\mathrm{D}$ and the spread found for the three or four determinations each for the 1.5 - and $0.2-\mathrm{g}$ samples of lot B. Also plotted in figure 2 are the recalculated small-sample values given by Newman [9]. These overlap the values obtained for zinc oxide $\mathrm{B}$ in the present series. Because of the low precision for small samples, little confidence can be placed in the apparent increase in heat of solution with sample weight shown in this part of the figure. Except for zinc oxide lot B, however, there is a significant difference in the results for $9-\mathrm{g}$ and $12-\mathrm{g}$ samples. Zinc oxide lots $\mathrm{E}$ and $\mathrm{F}$ were heated and ground at different times from the same source. For the same weight of sample there is no difference between $\mathrm{E}$ and $\mathrm{F}$ either in the same or in different acids. The increases in heat of solution between $9-\mathrm{g}$ and $12-\mathrm{g}$ samples for $\mathrm{E}$ and $\mathrm{F}$ are significant, however, although not as large as found for lot $\mathrm{A}$. The average difference in heat of solution between 9 - and $12-\mathrm{g}$ samples is about $0.28 \mathrm{cal} / \mathrm{g}^{2}$, and an effect of this magnitude should be considered when examining differences in the heats of solution of zinc oxide samples in this weight range.

\subsection{Recalculated Data}

Stenzel and Morris [4, table IV] determined the heat of solution of three different lots of zinc oxide over a period of about 6 months. Using, presumably, their various appropriate (by date) values of the energy equivalent of their calorimeter, they obtained heats of solution of $256.68 \pm 0.02,256.62$ \pm 0.06 , and $256.15 \pm 0.10 \mathrm{cal} / \mathrm{g}$, all originally assumed to be at $30{ }^{\circ} \mathrm{C}[4,5]$, but probably at a final calorimeter temperature of $31.5^{\circ} \mathrm{C}[8, \mathrm{pp} .579,580,589]$. The average of all nine determinations was $256.48 \pm 0.09$ cal $/$ g. Stenzel and Morris reported, however, that if the average of their seven reported energy-equiva- 


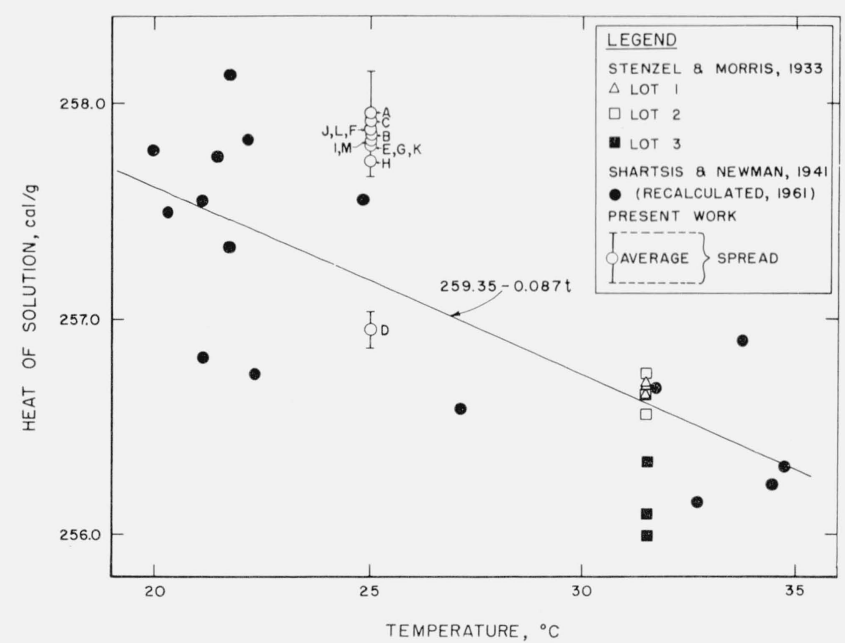

FIGURE 3. Eflect of temperature on the heat of solution of zinc oxide in nitric-hydrofluoric acid.

Recalculated data. The zinc oxide was heated $1 \mathrm{hr}$ at $950{ }^{\circ} \mathrm{C}$, ground to pass a No. 100 sieve, and reheated for $5 \mathrm{~min}$ before introduction. A ratio of 12 $\mathrm{ZnO} / 740 \mathrm{~g}$ acid was used except for Stenzel and Morris data Ind. Eng. Chem. Anal. Ed 6, 246-9 (1934)] for which the sample size is not known, and the temperature of reaction was assumed to be $31.5^{\circ} \mathrm{C} .(1 \mathrm{cal}=4.1840 \mathrm{j})$.

lent values was used to calculate all the heats of solution, the average heat of solution obtained was $256.1 \mathrm{cal} / \mathrm{g}$, almost the lowest of their individual experimental values. This computation could not be repeated by the present author since it was not known which of the calibration values was used for each heat-of-solution determination, and the individual corrected temperature rises per gram of zinc oxide could not be determined. It seems likely, however, that the reported average heat of solution of the zinc oxide should have been higher. A statistical test [15] of the few data given indicates that the heat of solution of their third lot of zinc oxide was significantly lower than those of the other two. If this lot were eliminated, the individual average value for the other two would be $256.65 \pm 0.03 \mathrm{cal} / \mathrm{g}$.

Shartsis and Newman [5] calibrated their calorimeter for average temperatures ranging from 14 to $35^{\circ} \mathrm{C}$. A new least-squares linear equation relating energv equivalent and average temperature has been obtained from a recalculation of their calibration data. Values of the energy equivalent calculated from this equation were used in recalculating their heats of solution. Figure 3 shows their heat-of-solution data as recomputed in 1961, plotted as ordinates against the final calorimeter temperature as abscissas. The equation of the least-squares straight line through these data is $y=259.35-0.087 t$, where $y$ is cal $/ \mathrm{g}$ and $t$ is ${ }^{\circ} \mathrm{C}$. The standard error of the slope is $0.013 \mathrm{cal} / \mathrm{g}-\mathrm{deg}$. The heat of solution of zinc oxide at $25^{\circ} \mathrm{C}$ from this equation is $257.2 \mathrm{cal} / \mathrm{g}$. The data as originally calculated gave a $25^{\circ} \mathrm{C}$ value of $257.0 \mathrm{cal} / \mathrm{g}$ and a slope of $0.087 \mathrm{cal} / \mathrm{g}-\mathrm{deg}$. Considering the scatter ${ }^{4}$ of their data, Shartsis and Newman did not wish to change the value 256.1 $\mathrm{cal} / \mathrm{g}$ given by Stenzel and Morris, but it seems now

4 The value 0.14 erroneously given as the standard deviation of the mean [5, p. 909] was actually $s_{y}^{2}$, the mean square of the deviations of the observed points about the line. The recalculated value is 0.16 , giving $0.4 \mathrm{cal} / \mathrm{g}$ as a measure of the scatter of the observed points about the fitted line. that they may have been overcautious, particularly if the latter authors' values were at $31.5^{\circ} \mathrm{C}$ as plotted in figure 3. The data shown in this figure indicate that the value $256.6 \mathrm{cal} / \mathrm{g}$ at $25^{\circ} \mathrm{C}$ is probably low.

\subsection{Comparison of Results}

The mean value for the heat of solution of zinc oxide obtained in this work is about half a percent higher than the specification value. If there is a systematic calibration error in the present work it has not been apparent, although the heat of solution found for potassium chloride is a quarter of a percent greater than the tentative "best" value. This difference, however, is not statistically significant. The energy equivalent for the calorimeter containing acid $A$ is 0.12 percent less than the values obtained for the other two batches, a difference the cause for which is not known. The heat of solution of the 9-g samples of zinc oxide A (table 6) in this acid was $257.37 \pm 0.044 \mathrm{cal} / \mathrm{g}$, in acid $\mathrm{B}$ it was 257.43 $\pm 0.065 \mathrm{cal} / \mathrm{g}$. It is perhaps improper to compare the still earlier work with $9-\mathrm{g}$ samples of zinc oxide A heated for $2 \mathrm{hr}$ at $950^{\circ} \mathrm{C}$ (table 3 ) with the results for standard-treated samples in table 6 , but table 3 shows that differences in temperature of heating are not critical, while the results for lot $\mathrm{H}$ agreed with the others in table 6 although it was heated for $17 \mathrm{hr}$ instead of $1 \mathrm{hr}$ before grinding. Making the comparison, the samples of zinc oxide lot $\mathrm{A}$ heated 2 hr at $950{ }^{\circ} \mathrm{C}$ (table 3 ) had an average heat of solution in acid $\mathrm{A}$ of $257.25 \pm 0.073 \mathrm{cal} / \mathrm{g}$, while after the standard treatment its heat of solution in the same acid was $257.37 \pm 0.044 \mathrm{cal} / \mathrm{g}$ (table 6). This difference also is not significant, although the effect of changing both the heat treatment and the acid is significant at the 5-percent probability level.

It seemed possible that there had been a real change in the purity or form of reagent zinc oxide with a corresponding change in its heat of solution since Stenzel and Morris determined it. Sample D of the present series, made by the American process directly from the ore, had a distinctly lower heat of solution than the others, exemplified by $\mathrm{B}$ and $\mathrm{C}$ made from the metal, but not as low as 256.6 $\mathrm{cal} / \mathrm{g}$. Sample D, however, was not of reagent grade and behaved differently on heating in that it did not shrink in the crucible, but remained a fine fluffy powder that could not be passed through a No. 100 sieve by shaking alone. Correspondence with a manufacturer has indicated that reagent zinc oxide made by the same process used today was well established on the market in 1933 and available to Stenzel and Morris. Thus it appears that there has probably been no substantial change in the purity or form of the reagent-grade zinc oxide used.

Stenzel and Morris do not give the final temperature of their calorimeter, but Biddle and Kelley [8], whose procedures the former authors were presumably following, operated their calorimeter ending at about $1.5 \mathrm{deg}$ above the bath temperature. Stenzel and Morris also do not state the quantity of zinc oxide used in their calorimeter, but in accordance with the usual procedure, it would have been an amount causing about the same temperature rise as 
a 6-g cement sample. On this basis, a sample of about $13-\mathrm{g}$ of $\mathrm{ZnO}$ would have been used in 1222.5 $\mathrm{g}$ of acid, and a final temperature of about $31.5{ }^{\circ} \mathrm{C}$ would have been reached. If the average heat of solution for their lots of zinc oxide No. 1 and No. 2, $256.65 \mathrm{cal} / \mathrm{g}$, is corrected to $25^{\circ} \mathrm{C}$ using the temperature coefficient $0.09 \mathrm{cal} / \mathrm{g}$-deg from figure 1 , and the value thus obtained is corrected from the $\mathrm{ZnO} /$ acid weight ratio of $13 / 1222.5$ to $7 / 425$ by the average difference found from figure 3 , a heat of solution of $257.6 \mathrm{cal} / \mathrm{g}$ is obtained. This value is in reasonable agreement with that found in the present work. The results obtained by Shartsis and Newman were less precise than those obtained either by Stenzel and Morris or in the present work, and the recalculated $25{ }^{\circ} \mathrm{C}$ value of $257.2 \mathrm{cal} / \mathrm{g}$ obtained from their work is essentially in agreement also.

\section{Conclusions}

Measurements have shown no significant difference between the heats of solution of heat-treated reagent zinc oxide from widely differing sources. As a consequence, heat-of-solution calorimeters calibrated with this substance in different laboratories, and even in different countries, should not be in disagreement because of differences in the calibrating standard. Accordingly, any differences found in portland-cement heat-of-hydration measurements between laboratories anywhere in the world are likely to be due to differences in sample-handling techniques between different laboratories or between different operators.

The heat of solution of $256.6 \mathrm{cal} / \mathrm{g}$ at $25^{\circ} \mathrm{C}$ assigned to "standard" heat-treated zinc oxide by various cement specifications appears to be about half a percent low. Consequently, the heats of hydration measured with calorimeters calibrated with $\mathrm{ZnO}$ are also low by the same percentage. Since the coefficient of variation for heats of hydration is likely to be substantially larger than 2 percent, this half-percent difference is not serious. However, heats of solution determined in electrically calibrated and in zinc oxide calibrated calorimeters will disagree, and this disagreement may cause concern.

The heat of solution of zinc oxide in nitric-hydrofluoric acids appears to be affected only slightly by heating the $\mathrm{ZnO}$ at temperatures between 310 and $950^{\circ} \mathrm{C}$, slight decreases in the heat of solution (when calculated to the $950{ }^{\circ} \mathrm{C}$ ignited weight) being offset by slight decreases in the content of residual volatile material as the temperature of heating is increased. Consequently small changes in the temperature or time of heating of the zinc oxide will be without significant effect on the calculated heat capacity of cement calorimeters.

Small changes in the $\mathrm{ZnO} /$ acid weight ratio from the specification value of $7 / 425$ are without significant effect from the standpoint of cement calorimetry, but changes as large as 25 percent from this ratio should be avoided.

The 1-hr heating of zinc oxide at $950{ }^{\circ} \mathrm{C}$ and its subsequent grinding and reheating can be eliminated from the specification. It would suffice to require only a 2-hr heating of the calorimeter sample with subsequent cooling in a desiccator for $2 \mathrm{hr}$ over magnesium perchlorate and weighing before introduction into the calorimeter.

The heat of solution of standard-heat-treated analytical-reagent-grade zinc oxide at $25^{\circ} \mathrm{C}$ in $\mathrm{HNO}_{3}$, $0.28 \mathrm{HF}, 26.4 \mathrm{H}_{2} \mathrm{O} \quad\left(8.0 \mathrm{ml} \quad 48 \% \mathrm{HF}+2.00 \mathrm{~N} \quad \mathrm{HNO}_{3}\right.$ to total $425.0 \mathrm{~g}$ ) at a $\mathrm{ZnO} /$ acid weight ratio of $7 / 425$ was measured as $257.82 \mathrm{cal} / \mathrm{g}$, with a standard error of $0.015 \mathrm{cal} / \mathrm{g}$. The temperature coefficient of this reaction is $-0.087 \mathrm{cal} / \mathrm{g}$-deg $\mathrm{C}$, with a standard error of $0.013 \mathrm{cal} / \mathrm{g}-\mathrm{deg} \mathrm{C}$. Independent measurement of these values by others would be desirable.

The assistance of John H. Gibb, guest worker, in preparing the recrystallized potassium chloride and participating in measurements of its heat of solution, is gratefully acknowledged. Thanks are also due to J. H. Welch of the Building Research Station, Garston, England, to F. Gille of the Forschungsinstitut der Zementindustrie, Dusseldorf, West Germany, and to Renichi Kondo of the Tokyo Institute of Technology, Tokyo, Japan, who graciously provided samples of reagent zinc oxide from their respective countries.

\section{References}

[1] Federal Test Method Standard No. 158a. Method 3101.1, General Services Administration, Washington, D.C. $(1960)$.

[2] ASTM Standards. Designation C 186-55. Heat of hydration of portland cement, American Society for Testing Materials, Philadelphia 3, Pa. (1960).

[3] British Standard No. 1370-1958, British Standards Institution, London (1958).

[4? R. W. Stenzel and S. B. Morris. Ind. Eng. Chem., Anal. Ed., 6, 246-49(1934).

[5] L. Shartsis and E. S. Newman, Proc. Am. Soc. Testing Materials 43, 905-16(1943).

[6] W. A. Roth and P. Chall, Z. Elektrochem. 34, 185-99 (1928).

[7] R. B. Peppler and E. S. Newman, J. Research NBS 26, 121-23(1951) RP2183.

[8] S. B. Biddle, Jr., and J. W. Kelly, Proc. Am. Soc. Testing Materials 33, 571-89(1933).

[9] E. S. Newman, J. Research NBS 62, 207-11(1959) RP2955.

[10] H. A. Berman and E. S. Newman, J. Research NBS 65A (Phys. and Chem.) No. 3, 197-207(1961).

[11] E. S. Newman and L. S. Wells, J. Research NBS 20, 825-36(1938) RP1107.

[12] E. S. Newman, J. Research NBS 5\%, 27-30(1956) RP2690.

[13] W. P. White, The Modern Calorimeter, Am. Chem. Soc. Monograph No. 49, The Chemical Catalog Co., New York (1928).

[14] F. D. Rossini, D. D. Wagman, W. H. Evans, S. Levine, and I. Jaffe, Selected values of chemical thermodynamic properties, NBS Circ. 500(1952).

[15] W. J. Youden, Statistical Methods for Chemists. p. 24 John Wiley \& Sons, New York, (1951).

[16] International Critical Tables. 3, 58; 5, 122, National Research Council (McGraw-Hill Book Co., New York, 1933).

[17] T. W. Parker and R. W. Nurse, Cement and Lime Manufacture, 26, No. 1,1-8 (1953).

[18] J. Coops, G. Somsen, and M. W. Tolk, The use of potassium chloride as a standard substance in solution calorimetry, Calorimetry Conference, Ottawa. (1961).

[19] Vivian Barfield, Preliminary Report, National Bureau of Standards, Calorimetry Conference, Ottawa. (1961).

(Paper 66A5-173) 